OPEN ACCESS

Edited by:

Agnieszka Ludwików,

Adam Mickiewicz University

in Poznañ, Poland

Reviewed by:

Taras P. Pasternak,

University of Freiburg, Germany

Sailendra Nath Sarkar,

University of Calcutta, India

${ }^{*}$ Correspondence:

Kisung Ko

ksko@cau.ac.kr

Specialty section:

This article was submitted to

Plant Biotechnology,

a section of the journal

Frontiers in Plant Science

Received: 27 September 2016

Accepted: 14 February 2017

Published: 28 February 2017

Citation:

Kang YJ, Kim D-S, Myung S-C and Ko K (2017) Expression of a Human

Prostatic Acid Phosphatase

(PAP)-IgM FC Fusion Protein in Plants

Using In vitro Tissue Subculture.

Front. Plant Sci. 8:274.

doi: $10.3389 / f p / s .2017 .00274$

\section{Expression of a Human Prostatic Acid Phosphatase (PAP)-IgM Fc Fusion Protein in Plants Using In vitro Tissue Subculture}

\author{
Yang J. Kang ${ }^{1}$, Deuk-Su Kim ${ }^{1}$, Soon-Chul Myung ${ }^{2}$ and Kisung Ko ${ }^{1 *}$ \\ ${ }^{1}$ Therapeutic Protein Engineering Laboratory, Department of Medicine, College of Medicine, Chung-Ang University, Seoul, \\ South Korea, ${ }^{2}$ Department of Urology, College of Medicine, Chung-Ang University, Seoul, South Korea
}

In this study, prostatic acid phosphatase (PAP), which is overexpressed in human prostate cancer cells, was cloned to be fused to the IgM constant fragment ( $F \mathrm{c})$ for enhancing immunogenicity and expressed in transgenic tobacco plants. Then, the transgenic plants were propagated by in vitro tissue subculture. Gene insertion and expression of the recombinant PAP-IgM Fc fusion protein were confirmed in each tested the first, second, and third subculture generations $\left(\mathrm{SG}_{1}, \mathrm{SG}_{2}\right.$, and $\mathrm{SG}_{3}$, respectively). Transcription levels were constantly maintained in the $\mathrm{SG}_{1}, \mathrm{SG}_{2}$, and $\mathrm{SG}_{3}$ leaf section (top, middle, and base ). The presence of the PAP-lgM Fc gene was also confirmed in each leaf section in all tested subculture generations. RNA expression was confirmed in all subculture generations using real-time PCR and quantitative real-time PCR. PAP-IgM FC protein expression was confirmed in all leaves of the $\mathrm{SG}_{1}, \mathrm{SG}_{2}$, and $\mathrm{SG}_{3}$ recombinant transgenic plants by using quantitative western blotting and chemiluminescence immunoassays. These results demonstrate that the recombinant protein was stably expressed for several generations of in vitro subculture. Therefore, transgenic plants can be propagated using in vitro tissue subculture for the production of recombinant proteins.

Keywords: subculture generation, propagation, transgenic plant, recombinant protein, prostatic acid phosphatase

\section{BACKGROUND}

Recombinant proteins are commonly produced in animal cells (Andersen and Krummen, 2002; Birch and Racher, 2006). However, production in animal cells is costly, and the cultures are susceptible to human pathogen contamination. Plants have also been effectively used as expression systems for large-scale production of recombinant proteins (Larrick and Thomas, 2001; Twyman et al., 2003; Fischer et al., 2004; Daniell et al., 2009; Ko et al., 2009; So et al., 2013; Lim et al., 2015; Park et al., 2015; Kim et al., 2016), and plant-based production has many advantages over other systems, including low biomass production costs and lack of human pathogen contamination (Twyman et al., 2003). Therefore, a wide range of recombinant biotherapeutic proteins, including industrial enzymes and new protein polymers, have been produced in plants (Ma et al., 2003). Similar to mammalian cell expression systems, plant biomass increases in an in vitro subculture system, and subculture can affect the protein expression level (Kim et al., 2011; 
Dorai and Ganguly, 2014). Although in vitro plant tissue subculture is an efficient method for clonal propagation, somaclonal variation generation occurred after quite prolong stage of unorganized growth, with a loss of transgene insertion and protein expression (Krishna et al., 2016). The recombinant proteins must be stably expressed in plants during in vitro growth so that the protein product can be extracted and purified. However, loss of the recombinant protein during plant tissue subculture is unpredictable, and sometimes, recombinant protein expression is unstable.

Prostatic acid phosphatase (PAP) is a glycoprotein that is synthesized in the epithelial cells of the prostate and is secreted into the seminal fluid (Vihko et al., 1988; McNeel et al., 2009). PAP is a prostate cancer antigen that is overexpressed by malignant prostate cell tissues and is often used as a therapeutic protein (Tarassoff et al., 2006; McNeel et al., 2009; Saif et al., 2014). In addition, due to its high expression in the prostate, PAP has been tested as a prostate cancer target antigen (Graddis et al., 2011). PAP-based peptide vaccination has been reported to induce antigen-specific T-cell responses and inhibit tumor growth in mice (Saif et al., 2014).

In this study, we examined the expression of a PAP-IgM Fc fusion protein in plant leaves from in vitro tissue subculture, as a vaccine candidate. The aim of this study was to determine whether PAP-IgM Fc fusion protein expression is stable over several in vitro subculture generations $\left(\mathrm{SG}_{1}, \mathrm{SG}_{2}\right.$, and $\left.\mathrm{SG}_{3}\right)$.

\section{MATERIALS AND METHODS}

\section{Construction of the PAP-IgM Fc Gene Expression Vector}

The synthetic DNA sequence encoding PAP (GenBank accession no. M34840.1) was cloned as a fusion to the Fc fragment of the human IgM $\mu$ chain (GenBank accession No. X57086.1). The PAP sequence was modified by the addition of an N-terminal extension encoding a signal peptide (MATQRRANPSSLHLITVFSLLAAVVSAEVD; Lu et al., 2012). The gene encoding PAP-IgM Fc was cloned under the control of the enhanced cauliflower mosaic virus (CaMV) 35S promoter and the tobacco etch virus 5'-leader sequence (TEV; Figure 1A). The PAP-IgM Fc expression cassette was subcloned into the HindIII and EcoRI restriction enzyme sites of the binary plant expression vector $\mathrm{pBI} 121$ to generate $\mathrm{pBI}$ PAP-IgM Fc. Then, the vector was transformed into competent Escherichia coli $\mathrm{DH} 5 \alpha$ cells for amplification.

\section{Plant Transformation}

The recombinant pBI PAP-IgM Fc vector was transferred into Agrobacterium tumefaciens strain LBA4404 by electroporation. Then, transgenic tobacco (Nicotiana tabacum) plants were generated by Agrobacterium-mediated transformation (Ko et al., 2003; Lu et al., 2012; So et al., 2013). Transgenic plant lines were selected on Murashige and Skoog (MS) medium $\left[30 \mathrm{~g} \cdot \mathrm{L}^{-1}\right.$ of Sucrose, $6 \mathrm{~g} \cdot \mathrm{L}^{-1}$ of Phyto agar, and $4.8 \mathrm{~g} \cdot \mathrm{L}^{-1}$ of MS B5 vitamin (Duchefa Biochemie, Haarlem, Netherlands)] containing $100 \mathrm{mg} \cdot \mathrm{L}^{-1} \mathrm{kanamycin}$ and $250 \mathrm{mg} \cdot \mathrm{L}^{-1}$ cefotaxime. Transgenic plants were grown in a chamber at constant temperature $\left(23^{\circ} \mathrm{C}\right)$ and light intensity of $50 \mu \mathrm{mol} \cdot \mathrm{m}^{-2} \cdot \mathrm{s}^{-1}$ under a long-day photoperiod (16:8 $\mathrm{h}$ light-dark cycle). Among the transgenic plants with high protein expression, three PAP-IgM Fc expressing transgenic lines (T502, T506, and T509) were randomly selected for in vitro tissue subculture.

\section{In vitro Subculture of PAP-IgM Fc Plants}

Transgenic plants expressing PAP-IgM Fc were grown in vitro as the first generation tissue culture $\left(\mathrm{SG}_{1}\right)$ in a Magenta $\mathrm{GA}-7$ vessel (Sigma-Aldrich, St. Louis, MO, USA) for 4 weeks. Plant stems were divided into three sections [top (T), middle (M), and base (BA)]. T, M, and BA plantlet stem pieces were transplanted into new media and grown as the second-generation tissue subculture $\left(\mathrm{SG}_{2}\right)$ for 2 weeks. This tissue subculture was repeated to generate the third generation $\mathrm{SG}_{3}$ (Figure 1A).

\section{Genomic DNA Extraction and PCR Analysis}

Leaf tissue samples were harvested from the top portion of transgenic and non-transgenic plantlets. Genomic DNA from fresh leaf tissue was isolated using a DNA extraction kit (RBC Bioscience, Seoul, South Korea) according to the manufacturer's protocol. The extracted genomic DNA was analyzed by polymerase chain reaction (PCR) to confirm the presence of the recombinant PAP-IgM Fc gene using the following primer pairs: forward primer $5^{\prime}$-GCC CTC GTT TTC AAG AAC TTG-3' and reverse primer $5^{\prime}$-CGG GAT CCT CAG TAG CAG GTG CCA GCT GTG-3'. The PCR was performed with 30 cycles of $94^{\circ} \mathrm{C}$ for $20 \mathrm{~s}, 62^{\circ} \mathrm{C}$ for $20 \mathrm{~s}$, and $72^{\circ} \mathrm{C}$ for 120 s. Genomic DNA isolated from non-transgenic plant leaves was used as the negative control, and the pBI PAP-IgM Fc gene was used as a positive control. The expected size of PAP-IgM Fc PCR product was 1,685 bp. PCR analysis was performed for more than three times.

\section{Real Time-PCR (RT-PCR) and Quantitative Real Time-PCR (RT-qPCR) Analyses}

Leaf tissue samples were used from each top portion of transgenic plantlets. Total RNA was isolated from the leaves of transgenic plant samples $\left(S_{1}, S_{2}\right.$, and $\left.S_{3}\right)$ using an Rneasy plant mini kit (Quagen, Valencia, CA) according to the manufacturer's recommendations, and the isolated RNA samples were stored at $-80^{\circ} \mathrm{C}$. Genomic DNA removal and cDNA synthesis were performed using the Quantitect reverse transcription kit (Quagen, Valencia, CA) according to the manufacturer's protocol. Each RNA sample was used as a template for RT-PCR and RT-qPCR analyses. RT-PCR and RT-qPCR reactions were performed using the Maxime PCR premix kit (Intron Biotechnology, Seoul, South Korea) and Rotor-Gene SYBR Green PCR kit (Quagen, Valencia, CA), respectively. PAP-IgM Fc primers were as follows: $5^{\prime}$-CTC ATG CTA CCT GGT TGC AG-3'; forward, 5'-GGT GGG ACG AAG ACG CTC A-3'. Quantitative RT-PCR was analyzed using real-time PCR machine (Rotor-Gene Q, Quagen) with the following cycling parameters: 


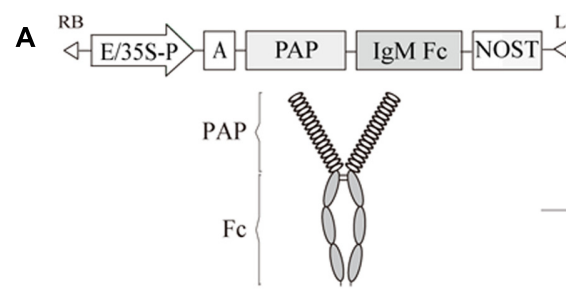

Plant expression vector $\mathrm{pBI}$ PAP-IgM Fc and expected PAP-IgM Fc protein structure
LB

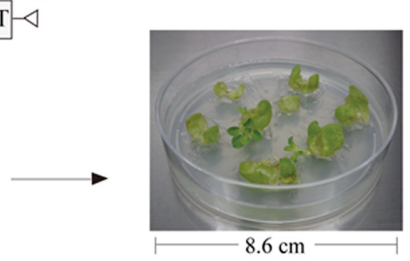

Tobacco regenerated transformant

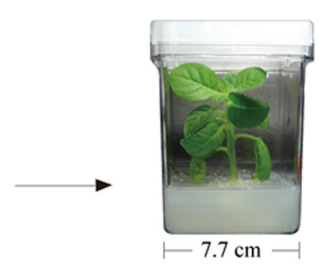

In vitro transgenic plant expressing PAP-IgM Fc

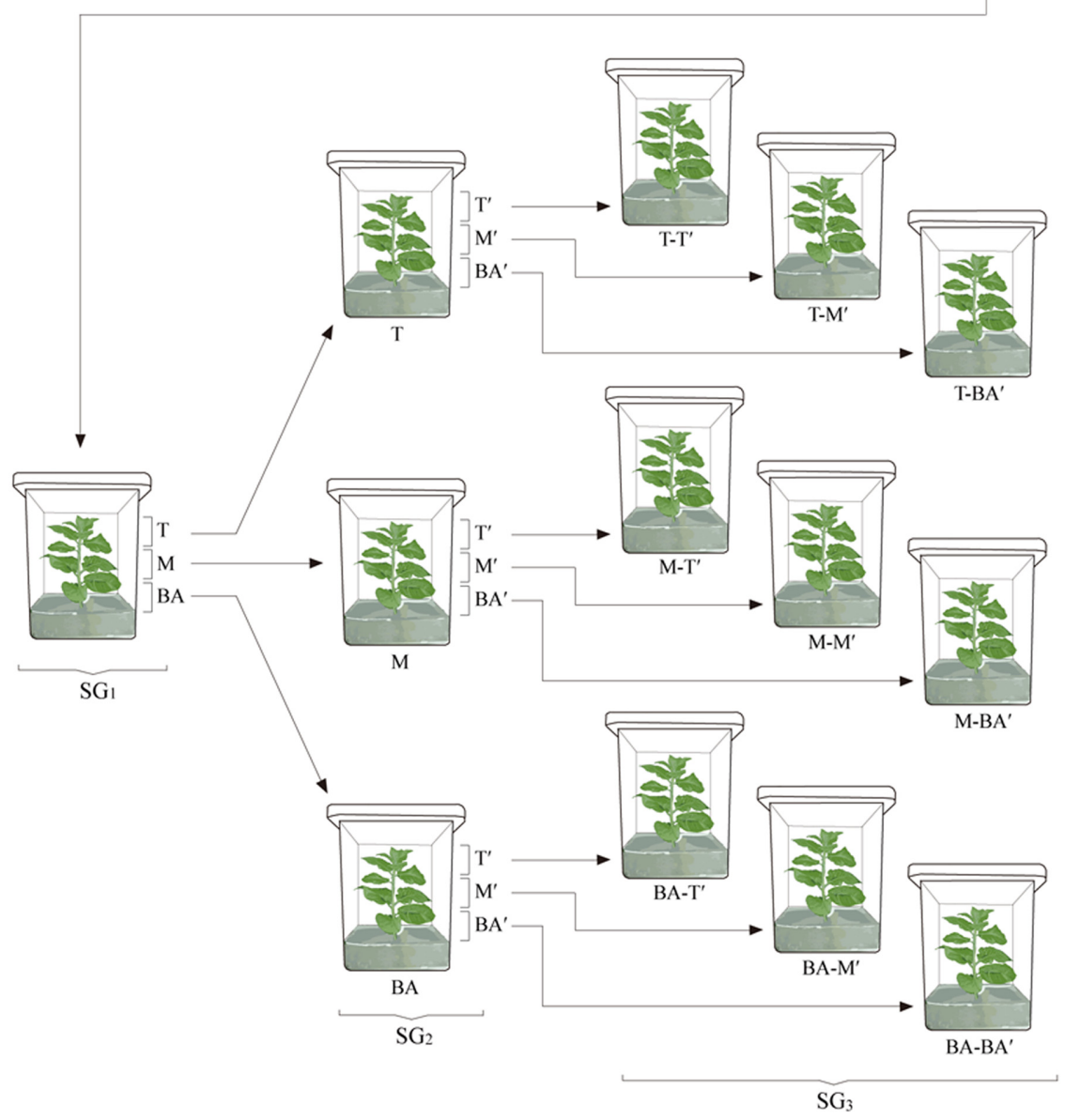

B

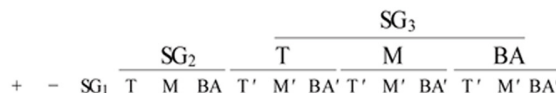

T502

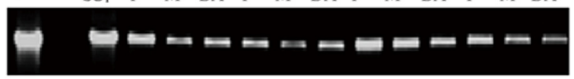

T506

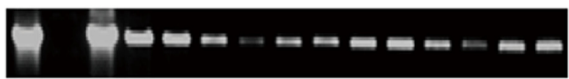

T509
C

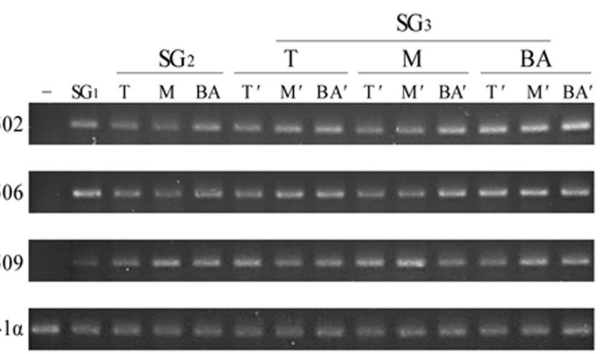

FIGURE 1 | Schematic diagram of the plant expression vector, the structure of the recombinant prostatic acid phosphatase (PAP)-IgM Fc fusion protein, plant transformation procedure, and sampling procedure for top, middle, and base leaf tissues in the various subculture generations $\left(\mathrm{SG}_{1}\right.$, $\mathbf{S G}_{\mathbf{2}}$, and $\mathbf{S G}_{\mathbf{3}}$ ). (A) The PAP-IgM Fc gene expression cassette in the binary pBl121 plant vector containing the cauliflower mosaic virus $35 \mathrm{~S}$ promoter with a duplicated enhancer region (E/35S-P), the untranslated leader sequence of the tobacco etch virus, and the nopaline synthase gene terminator (NOST). Expected structure of the recombinant PAP-IgM Fc fusion protein, with a spring-shaped region (PAP) and a gray oval region (IgM Fc). A PAP-IgM Fc transgenic tobacco 


\section{FIGURE 1 | Continued}

plantlet growing on kanamycin selection medium in a Magenta GA-7 vessel. T, top SG s $_{1}$ stem sample; $M$, middle $\mathrm{SG}_{1}$ stem sample; $B$, base $S G_{1}$ stem sample; $T-T^{\prime}, T$ of the $S G_{2}$ stem produced from the $T$ of the $S G_{1}$ stem; $T-M^{\prime}, M$ of the $S G_{2}$ stem produced from the $T$ of the $S G_{1}$ stem; $T-B A^{\prime}, B^{\prime}$ of the $S G_{2}$ stem produced from the $T$ of the $S G_{1}$ stem; $M-T^{\prime}, T$ of the $S G_{2}$ stem produced from the $M$ of the $S G_{1}$ stem; $M-M$ ', $M$ of the $S G_{2}$ stem produced from the $M$ of the $S G_{1}$ stem; $M-B A^{\prime}, B A$ of the $S G_{2}$ stem produced from the $M$ of the $S G_{1}$ stem; $B A-T^{\prime}, T$ of the $S G_{2}$ stem produced from the $B A$ of the $S G_{1}$ stem; $B A-M$ ', $M$ of the $S G_{2}$ stem produced from the $B A$ of the $S G_{1}$ stem; and $B A-B A$ ', $B A$ of the $S_{2}$ stem produced from the $B A$ of the $S G_{1}$ stem. The circle with the dotted line indicates the part of the leaf tissue of the top portion that was harvested for analyses. (B) polymerase chain reaction (PCR) analysis to confirm the presence of the PAP-IgM Fc gene in tissues from subculture generations $\mathrm{SG}_{1}, \mathrm{SG}_{2}$, and $\mathrm{SG}_{3}$. PAP-IgM Fc (1,786 bp): positive control (+), pBI PAP-IgM Fc recombinant vector in DH5 $\alpha$ competent cells, negative control (-), and non-transgenic tobacco plant (NT). The loading amount was $5 \mu \mathrm{L}$ per sample. (C) Reverse transcription (RT)-PCR. Gene expressions were analyzed using $\mathrm{RT}-\mathrm{PCR}$ of $\mathrm{SG}_{1}, \mathrm{SG}_{2}$, and $\mathrm{SG}_{3}$ leaf section. The negative control (-) consists of mRNA of a non-transgenic tobacco plant. The $E F-1 \alpha$ gene was used as a housekeeping gene.

$5 \mathrm{~min}$ at $95^{\circ} \mathrm{C}, 5 \mathrm{~s}$ at $95^{\circ} \mathrm{C}, 10 \mathrm{~s}$ at $60^{\circ} \mathrm{C}$, and 40 cycles of $5 \mathrm{~s}$ at $95^{\circ} \mathrm{C}$ and $10 \mathrm{~s}$ at $60^{\circ} \mathrm{C}$. The elongation factor $1-\alpha(\mathrm{EF}-1 \alpha)$ gene was used as a housekeeping gene. RT PCR and RT-qPCR analyses were performed for 3 times.

\section{Quantitative Immunoblot Analysis}

The PAP-IgM Fc protein expression level in transgenic lines T502, T506, and T509 was investigated using immunoblot analysis. Leaf samples $(100 \mathrm{mg}$ ) were harvested from the plantlet top and homogenized in $300 \mu \mathrm{L}$ of $1 \times$ PBS $(137 \mathrm{mM} \mathrm{NaCl}, 10 \mathrm{mM}$ $\mathrm{Na}_{2} \mathrm{HPO}_{4}, 2.7 \mathrm{mM} \mathrm{KCl}$, and $2 \mathrm{mM} \mathrm{KH}_{2} \mathrm{PO}_{4}$ ) to extract total soluble proteins. PAP-IgM Fc leaf extracts were boiled with $5 \times$ protein loading buffer ( $1 \mathrm{M}$ Tris- $\mathrm{HCl}, 50 \%$ glycerol, $10 \% \mathrm{SDS}$, $5 \%$ 2-mercaptoethanol, and $0.1 \%$ bromophenol blue) for $10 \mathrm{~min}$ and cooled for $2 \mathrm{~min}$. Total soluble proteins were separated by $10 \%$ SDS-PAGE and transferred to a nitrocellulose membrane (Millipore, Billerica, MA, USA). Membranes were incubated with $5 \%$ skim milk (Sigma, St. Louis, MO, USA) in $1 \times$ PBS buffer at $4^{\circ} \mathrm{C}$ overnight. Blots were incubated with a goat anti-human $\operatorname{IgM}$ ( $\mu$ chain) antibody conjugated to horseradish peroxidase (Abcam Inc., Cambridge, MA, USA) diluted 1:5,000 in $1 \times$ PBS solution for $2 \mathrm{~h}$ at room temperature (Figure 2A). After three 10min washes, proteins were detected with the SuperSignal West Pico Chemiluminescent Substrate (Thermo Scientific, Rockford, IL, USA) and visualized by exposing the membrane to X-ray film (Fuji, Tokyo, Japan). Leaf tissue extract from non-transgenic plants was used as a negative control. Detected protein bands were digitized as an electronic image, and band intensity was measured using ImageJ software (National Institutes of Health, Bethesda, MD, USA). Immunoblot analysis was performed for more than three times.

\section{Chemiluminescence Immunoassay}

Expression of PAP-IgM Fc in plant leaf tissue was analyzed using a chemiluminescence immunoassay (CLIA). Leaf samples from PAP-IgM Fc transgenic plants were harvested from the plantlet top ( $\mathrm{T}$ of $\mathrm{SG}_{2}$ and $\mathrm{T}-\mathrm{T}, \mathrm{M}$-T', and $\mathrm{BA}-\mathrm{T}^{\prime}$ of $\mathrm{SG}_{3}$; Figure 1A) and homogenized in $300 \mu \mathrm{L}$ of $1 \times$ PBS $(137 \mathrm{mM} \mathrm{NaCl}$, $10 \mathrm{mM} \mathrm{Na} 2 \mathrm{HPO}_{4}, 2.7 \mathrm{mM} \mathrm{KCl}$, and $2 \mathrm{mM} \mathrm{KH}_{2} \mathrm{PO}_{4}$ ) for total soluble protein extraction. All samples were diluted 1:100 in $1 \times$ PBS solution. A cuvette containing the anti-PAP coated beads (Siemens Healthcare Diagnostics Inc., Llanberis, UK) was incubated with PAP-IgM Fc and an anti-PAP antibody conjugated to alkaline phosphatase for $30 \mathrm{~min}$ at $37^{\circ} \mathrm{C}$ (Figure 2F). After the antibodies were removed and the beads were washed in deionized distilled water as a centrifugal washing buffer, the PAP-IgM Fc proteins were detected using the chemiluminescent substrate. The samples were analyzed on an IMMULITE $2000 \mathrm{xpi}$ (Siemens Healthcare Diagnostic Inc., Flanders, NJ, USA). CLIA was performed for more than three times.

\section{Statistical Analysis}

All values are shown as the mean \pm SD. Recombinant PAP-IgM Fc protein expression in transgenic plant leaves was compared by using the unpaired $t$-test, and $p$ values less than 0.01 (***) $^{* *}$ or $0.05\left(^{* *}\right)$ were considered statistically significant. Statistical significance was assessed using Excel (Microsoft Office Excel 2013; Microsoft Corporation, Redmond, WA, USA).

\section{RESULTS}

\section{Confirmation of PAP-IgM Fc Gene Presence}

Transgenic tobacco plant lines were obtained by Agrobacteriummediated transformation with plant expression vectors carrying PAP-IgM Fc. Genomic DNA extracted from three transgenic lines (T502, T506, and T509) was analyzed by PCR to confirm insertion of the PAP-IgM Fc transgene. The PAP-IgM Fc gene was detected in the top leaves of each subculture generation $\left(\mathrm{SG}_{1}\right.$, $\mathrm{SG}_{2}$, and $\mathrm{SG}_{3}$ ) obtained from the $\mathrm{T}, \mathrm{M}$, and $\mathrm{BA}$ stems harvested from tobacco transgenic plants $\left(\mathrm{SG}_{1}\right)$. The size of the PAP-IgM Fc PCR product in the genome of the transgenic plants was 1,685 bp (Figure 1B). No PAP-IgM Fc PCR product was detected in non-transgenic plants.

\section{Gene Transcription Level Analysis of PAP-IgM Fc in All Subculture Generations $\left(\mathrm{SG}_{1}, \mathbf{S G}_{2}\right.$, and $\left.\mathbf{S G}_{3}\right)$}

In real-time PCR and quantitative real-time PCR, the relative transcription level was observed in the top portions of all subculture generations $\left(\mathrm{SG}_{1}, \mathrm{SG}_{2}\right.$, and $\left.\mathrm{SG}_{3}\right)$ leaf tissues (Supplementary Figure S1). The transgene was not detected in non-transgenic plant (Figure 1C). RT-PCR product of the expected size of PAP-IgM Fc was detected in all samples of transgenic plants (T502, T506, and T509; Figure 1C). In RT-qPCR, the PAP-IgM Fc transcriptional levels were consistently higher than 0.9 level in $\mathrm{SG}_{1}, \mathrm{SG}_{2}$, and $\mathrm{SG}_{3}$ leaf section ( $T, M$, and BA; Supplementary Figure $S 1$ ). Non-transgenic plant showed no PAP-IgM Fc signal. 
A

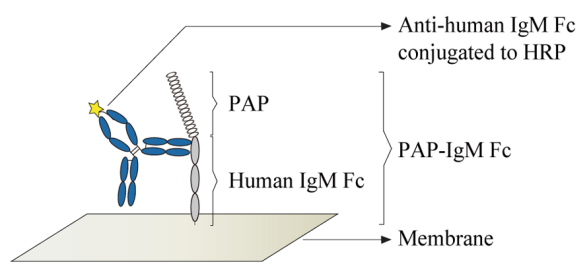

C

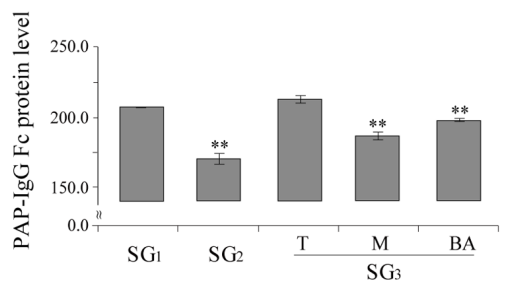

E

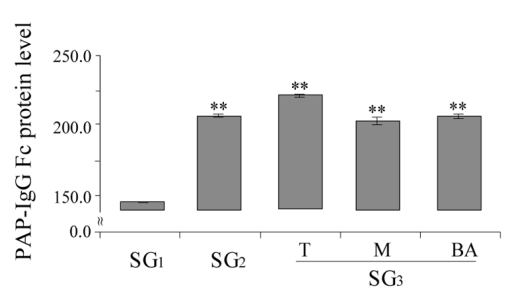

B

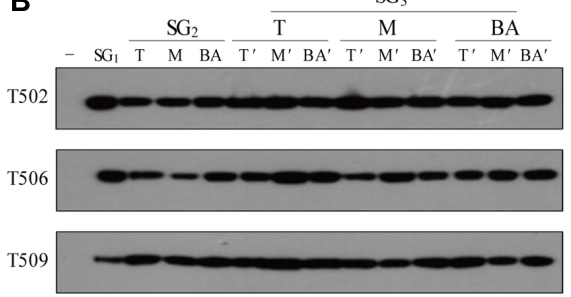

D

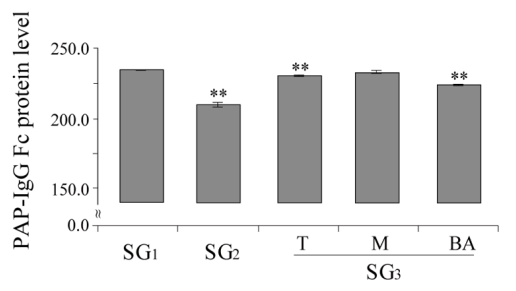

$\mathbf{F}$

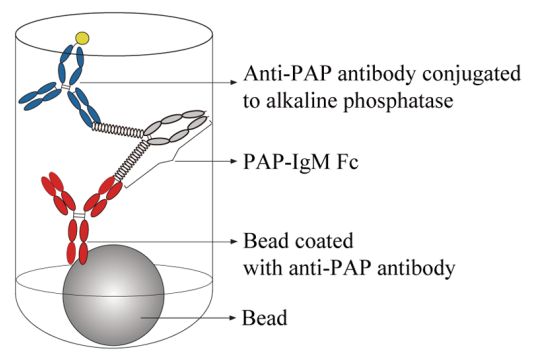

G

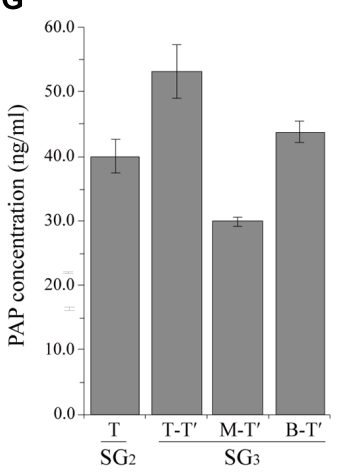

H

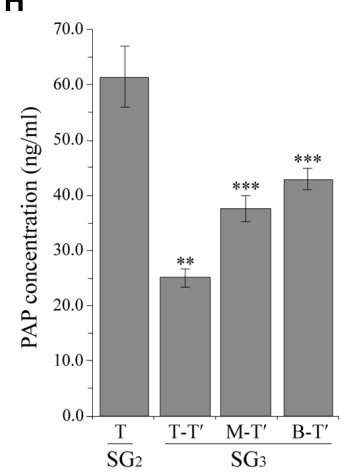

I

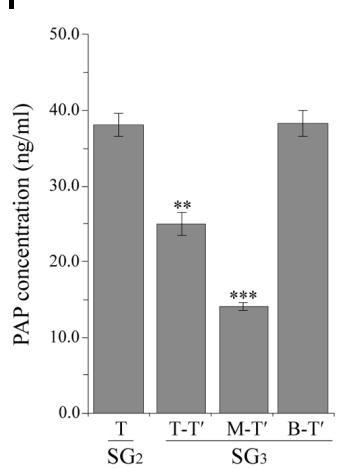

FIGURE 2 | Densitometry analysis of PAP-IgM Fc protein expression levels in the tissues of plantlets from subculture generations $\mathrm{SG}_{1}, \mathrm{SG}_{2}$, and $\mathrm{SG}_{3}$ (A-E) and chemiluminescence immunoassay (CLIA) to confirm PAP-IgM Fc protein expression in various leaf tissues from subculture (T of $S G_{2}$ and T-T, M-T', and BA-T' of $S_{3}$ protein expression $S_{3}(\mathbf{F}-\mathbf{l})$. (A) Illustration showing the interaction between PAP-IgM Fc and the anti-human IgM antibody conjugated to horseradish peroxidase (HRP) in the western blot. (B) Western blot analysis to confirm PAP-IgM Fc protein expression in top (T), middle (M), and base (BA) stem tissues from different subculture generations $\left(\mathrm{SG}_{1}, \mathrm{SG}_{2}\right.$, and $\left.\mathrm{SG}_{3}\right)$. Negative control $(-)$ and non-transgenic plant (NT). PAP-IgM Fc (83 kDa) was detected with HRP-conjugated goat anti-human IgM ( $\mu$ chain) immunoglobulin. Black arrowheads indicate the PAP-lgM Fc protein band (83 kDa). Expression levels of PAP-lgM Fc in T502 (C), T506 (D), and T509 (E) leaf tissues were assessed by western blotting with an anti-human IgM ( $\mu$ chain) immunoglobulin conjugated to HRP. Protein expression rates in the three PAP-IgM FC transgenic lines were calculated based on the protein band density in the western blot analysis. (F) Illustration of the double sandwich CLIA. The interaction between PAP-IgM Fc and the anti-human IgM antibody conjugated to alkaline phosphatase. The expression in the transgenic lines T502 (G), T506 (H), and T509 (I) PAP-IgM Fc proteins in transgenic plants from the top of $\mathrm{SG}_{2}$ and $\mathrm{SG}_{3}$. Data are the mean and standard error $\left({ }^{* * *} p<0.01,{ }^{* *} p<0.05, t\right.$-test).

\section{Confirmation of PAP-IgM Fc Protein Expression}

PAP-IgM Fc protein expression in leaf samples from transgenic plants was analyzed by western blotting. All transgenic plant lines harboring the PAP-IgM Fc transgene showed a protein band of approximately $83 \mathrm{kDa}$ (Figure 2B). Recombinant PAP-IgM Fc fusion proteins were expressed in all subculture generations $\left(\mathrm{SG}_{1}\right.$, $\mathrm{SG}_{2}$, and $\mathrm{SG}_{3}$ ) obtained from the $\mathrm{T}, \mathrm{M}$, and $\mathrm{BA}$ stems of $\mathrm{SG}_{1}$ 
transgenic plants (Figure 2B). No PAP-IgM Fc protein band was detected in non-transgenic plants, which were used as a negative control (Figure 2B).

\section{Densitometry Analysis of PAP-IgM Fc Protein Expression Levels in $\mathbf{S G}_{1}, \mathbf{S G}_{2}$, and $\mathbf{S G}_{3}$}

Quantitative western blot analysis was performed to determine the expression level of the recombinant PAP-IgM Fc fusion protein in the top leaves of $\mathrm{SG}_{1}, \mathrm{SG}_{2}$, and $\mathrm{SG}_{3}$ (Figure $2 \mathrm{~B}$ ). The intensity of the PAP-IgM Fc fusion protein bands in the top leaf samples was quantified using Image $J$ software. Although the PAP-IgM Fc recombinant protein expression level differed slightly among the $\mathrm{SG}_{1}, \mathrm{SG}_{2}$, and $\mathrm{SG}_{3}$ samples, all leaf samples showed stable expression of the recombinant protein (Figures 2C-E).

\section{Quantitative CLIA of PAP-IgM Fc in Transgenic Plant Leaves}

A CLIA was performed to quantify the expression of recombinant PAP-IgM Fc protein in the transgenic leaves of $\mathrm{SG}_{2}$ and $\mathrm{SG}_{3}$ plants. In T502, PAP-IgM Fc expression levels in each leaf position were slightly different. However, the mean values at each position in $\mathrm{SG}_{3}$ were not significantly different (Figure 2G). In T506, the PAP-IgM Fc expression levels were significantly different at each leaf position, and the mean values at each position in $\mathrm{SG}_{3}$ were significantly different (Figure $\mathbf{2 H}$ ). In T509, the PAP-IgM Fc expression levels in $\mathrm{SG}_{2}, \mathrm{~T}^{-} \mathrm{T}^{\prime}$ of $\mathrm{SG}_{3}$, and $\mathrm{M}-\mathrm{T}$ of $\mathrm{SG}_{3}$ differed. However, the mean values at all positions were not significantly different (Figure 2I). Overall, the expression of the recombinant PAP-IgM Fc fusion protein was maintained without loss in all in vitro SG samples (Figures 2G-I).

\section{DISCUSSION}

This study demonstrated that the production of different subculture generations of transgenic plants did not affect the expression of the recombinant PAP-IgM Fc fusion protein. The fusion of antigenic protein to IgM Fc can assembled to form large quaternary circular protein enhancing immunogenicity (David et al., 2011). The PAP is a PAP glycoprotein fused to the Fc fragment of the human IgM immunoglobulin. The PAP-IgM Fc gene was constitutively expressed under the control of the enhanced CaMV 35S promoter (Lu et al., 2012; Lim et al., 2015). The N-terminus of PAP was fused to a signal peptide.

In this study, we hypothesized that PAP-IgM Fc expression in transgenic plants would be stable through several generations produced by in vitro tissue subculture. With this in mind, each cultured stem section ( $T, M$, and BA) was transplanted and grown to investigate the stability of the transgene insertion and transgenic protein expression. PCR analysis confirmed that the recombinant PAP-IgM Fc gene insertion was stable in all tested subculture generations $\left(\mathrm{SG}_{1}, \mathrm{SG}_{2}\right.$, and $\left.\mathrm{SG}_{3}\right)$. In vitro subcultured transgenic plants may lose the recombinant gene during propagation (Fladung and Kumar, 2002; Zeng et al.,
2010; Martinelli et al., 2015). Loss of recombinant genes may occur because they are not strongly attached to the genomic DNA of plant cells (Doran, 2006). However, in this study, stable insertion of the PAP-IgM Fc gene was confirmed in all subculture generations. RT-PCR and RT-qPCR analysis were applied to investigate whether the mRNA levels of the PAP-IgM Fc gene expression at all subculture generations $\left(\mathrm{SG}_{1}\right.$, $\mathrm{SG}_{2}$, and $\left.\mathrm{SG}_{3}\right)$. The mRNA levels slightly differed at each subculture generations. However, transcription levels in all transgenic plants were constantly maintained at each subculture generation (Supplementary Figure S1). These results indicate that the PAP-IgM Fc transgene was not deleted during tissue propagation.

Immunoblot analysis and CLIA were conducted to investigate whether the PAP-IgM Fc fusion protein was expressed in the different subculture generations. The protein expression levels slightly differed at leaf tissue positions among $\mathrm{SG}_{1}, \mathrm{SG}_{2}$, and $\mathrm{SG}_{3}$. Such of the PAP-IgM Fc protein level is due to leaf tissue position and developmental stage, at which water content and plant cell number might be variable (Streatfield, 2007; Lim et al., 2015). Thus, in the future normalization for protein level quantification should be optimized, which can precisely calculate amount of recombinant protein per amount of total soluble protein in plant tissue (Alkanaimsh et al., 2016). In addition, the protein level might be fluctuated by variation factors, which are total soluble protein levels to be hardly controlled because of low ratio between leaf tissue material weight and homogenizing buffer volume in this study. However, all leaf samples harvested from the top portion of the plants showed stable expression of the PAP-IgM Fc recombinant protein. In addition, the PAP-IgM Fc recombinant protein was expressed without degradation in a consistent pattern in all subculture generations ( $\mathrm{SG}_{1}, \mathrm{SG}_{2}$, and $\mathrm{SG}_{3}$ ). The PAP expression levels in each plant sample, as quantified by western blotting, were correlated with the PAP levels detected by CLIA (data not shown). This shows that both these quantitative methods are reliable for confirming PAP expression in transgenic plant tissues.

Plant expression systems are advantageous both in terms of safety and production cost, when compared to conventional cell systems, such as yeast, mammalian, and insect cells (Twyman et al., 2003; Ko, 2014). In animal cell systems, loss of recombinant protein expression often occurs during subculture due to deletion of the recombinant transgenes (Heller-Harrison et al., 2009; Kim et al., 2011; Dorai and Ganguly, 2014).

The ultimate purpose of in vitro plant tissue subculture is the mass propagation of transgenic plants. However, somatic variations that occur during in vitro subculture can alter the genetic components and protein expression. Therefore, expression of the recombinant protein in the transgenic plants must be confirmed through in vitro subculture.

Taken together, the transgenic plants obtained through in vitro tissue subculture showed that the transgene and transgenic protein expression were stable. Thus, transgenic plants can be used to produce highly valuable therapeutic recombinant proteins via in vitro subculture. PAP is highly expressed in human prostate cancer cells, which can be a promising vaccine candidate. 
In addition, PAP itself can be used as one of prostate cancer indicators in medical diagnosis. Thus, plant-derived recombinant PAP-IgM Fc fusion protein can be highly useful in both research medical and purposes.

\section{AUTHOR CONTRIBUTIONS}

YK contributed for acquisition of data and writing of manuscript. D-SK contributed for acquisition of data and interpreted data. S-CM analyzed and interpreted data, and KK made substantial contributions to conception and design of the study.

\section{REFERENCES}

Alkanaimsh, S., Karuppanan, K., Guerrero, A., Tu, A. M., Hashimoto, B., Hwang, M. S., et al. (2016). Transient expression of tetrameric recombinant human butyrylcholinesterase in Nicotiana benthamiana. Front. Plant Sci. 7:743. doi: 10.3389/fpls.2016.00743

Andersen, D. C., and Krummen, L. (2002). Recombinant protein expression for therapeutic applications. Curr. Opin. Biotechnol. 13, 117-123. doi: 10.1016/ S0958-1669(02)00300-2

Birch, J. R., and Racher, A. J. (2006). Antibody production. Adv. Drug Deliv. Rev. 58, 671-685. doi: 10.1016/j.addr.2005.12.006

Daniell, H., Singh, N. D., Mason, H., and Streatfield, S. J. (2009). Plant-made vaccine antigens and biopharmaceuticals. Trends Plant Sci. 14, 669-679. doi: 10.1016/j.tplants.2009.09.009

David, N. A. M., Czajkowsky, D. M., Andersen, J. T., Shi, J., El-Faham, M., Doenhoff, M., et al. (2011). Polymeric human Fc-fusion proteins with modified effector functions. Sci. Rep. 1:124. doi: 10.1038/srep 00124

Dorai, H., and Ganguly, S. (2014). Mammalian cell-produced therapeutic proteins: heterogeneity derived from protein degradation. Curr. Opin. Biotechnol. 30, 198-204. doi: 10.1016/j.copbio.2014.07.007

Doran, P. M. (2006). Foreign protein degradation and instability in plants and plant tissue cultures. Trends Biotechnol. 24, 426-432. doi: 10.1016/j.tibtech.2006. 06.012

Fischer, R., Stoger, E., Schillberg, S., Christou, P., and Twyman, R. M. (2004). Plantbased production of biopharmaceuticals. Curr. Opin. Plant Biol. 7, 152-158. doi: 10.1016/j.pbi.2004.01.007

Fladung, M., and Kumar, S. (2002). Gene stability in transgenic aspenpopulus-III. T-DNA repeats influence transgene expression differentially among different transgenic lines. Plant Biol. 4, 329-338. doi: 10.1055/s-200232329

Graddis, T. J., Mcmahan, C. J., Tamman, J., Page, K. J., and Trager, J. B. (2011). Prostatic acid phosphatase expression in human tissues. Int. J. Clin. Exp. Pathol. 4, 295-306.

Heller-Harrison, R. A., Crowe, K., Cooley, C., Hone, M., Mccarthy, K., and Leonard, M. (2009). Managing cell line instability and its impact during cell line development. BioPharm Int. Suppl. 22, 1-12.

Kim, D.-S., Song, I., Kim, J., Kim, D.-S., and Ko, K. (2016). Plant recycling for molecular biofarming to produce recombinant anti-cancer mAb. Front. Plant Sci. 7:1037. doi: 10.3389/fpls.2016.01037

Kim, M., O'Callaghan, P. M., Droms, K. A., and James, D. C. (2011). A mechanistic understanding of production instability in $\mathrm{CHO}$ cell lines expressing recombinant monoclonal antibodies. Biotechnol. Bioeng. 108, 24342446. doi: 10.1002/bit.23189

Ko, K. (2014). Expression of recombinant vaccines and antibodies in plants. Monoclon. Antib. Immunodiagn. Immunother. 33, 192-198. doi: 10.1089/mab. 2014.0049

Ko, K., Brodzik, R., and Steplewski, Z. (2009). Production of antibodies in plants: approaches and perspectives. Curr. Top. Microbiol. Immunol. 332, 55-78. doi: 10.1007/978-3-540-70868-1_4

\section{ACKNOWLEDGMENT}

This research was supported by a Chung-Ang University Graduate Research Scholarship in 2016 and the National Research Foundation of Korea (No. NRF-2014R1A2A1A110 52922 ) by the Korean Government (MEST).

\section{SUPPLEMENTARY MATERIAL}

The Supplementary Material for this article can be found online at: http://journal.frontiersin.org/article/10.3389/fpls.2017.00274/ full\#supplementary-material

Ko, K., Tekoah, Y., Rudd, P. M., Harvey, D. J., Dwek, R. A., Spitsin, S., et al. (2003). Function and glycosylation of plant-derived antiviral monoclonal antibody. Proc. Natl. Acad. Sci. U.S.A. 100, 8013-8018. doi: 10.1073/pnas.0832472100

Krishna, H., Alizadeh, M., Singh, D., Singh, U., Chauhan, N., Eftekhari, M., et al. (2016). Somaclonal variations and their applications in horticultural crops improvement. 3 Biotech 6, 1-18. doi: 10.1007/s13205-016-0389-7

Larrick, J. W., and Thomas, D. W. (2001). Producing proteins in transgenic plants and animals. Curr. Opin. Biotechnol. 12, 411-418. doi: 10.1016/S0958-1669(00) 00236-6

Lim, C. Y., Lee, K. J., Oh, D. B., and Ko, K. (2015). Effect of the developmental stage and tissue position on the expression and glycosylation of recombinant glycoprotein GA733-FcK in transgenic plants. Front. Plant Sci. 5:778 doi: 10. 3389/fpls.2014.00778

Lu, Z., Lee, K. J., Shao, Y., Lee, J. H., So, Y., Choo, Y. K., et al. (2012). Expression of GA733-Fc fusion protein as a vaccine candidate for colorectal cancer in transgenic plants. J. Biomed. Biotechnol. 2012:364240. doi: 10.1155/2012/ 364240

Ma, J. K., Drake, P. M., and Christou, P. (2003). The production of recombinant pharmaceutical proteins in plants. Nat. Rev. Genet. 4, 794-805. doi: 10.1038/ nrg1177

Martinelli, L., Candioli, E., Costa, D., and Minafra, A. (2015). Stable insertion and expression of the movement protein gene of Grapevine Virus A (GVA) in grape (Vitis rupestris S.). Visit 41, 189-193.

McNeel, D. G., Dunphy, E. J., Davies, J. G., Frye, T. P., Johnson, L. E., Staab, M. J., et al. (2009). Safety and immunological efficacy of a DNA vaccine encoding prostatic acid phosphatase in patients with stage D0 prostate cancer. J. Clin. Oncol. 27, 4047-4054. doi: 10.1200/JCO.2008.19.9968

Park, S. R., Lim, C. Y., Kim, D. S., and Ko, K. (2015). Optimization of ammonium sulfate concentration for purification of colorectal cancer vaccine candidate recombinant protein GA733-FcK isolated from plants. Front. Plant Sci. 6:1040. doi: $10.3389 /$ fpls. 2015.01040

Saif, J., Vadakekolathu, J., Rane, S. S., Mcdonald, D., Ahmad, M., Mathieu, M., et al. (2014). Novel prostate acid phosphatase-based peptide vaccination strategy induces antigen-specific T-cell responses and limits tumour growth in mice. Eur. J. Immunol. 44, 994-1004. doi: 10.1002/eji.201343863

So, Y., Lee, K.-J., Kim, D.-S., Lee, J.-H., Oh, D.-B., Hwang, K.-A., et al. (2013). Glycomodification and characterization of anti-colorectal cancer immunotherapeutic monoclonal antibodies in transgenic tobacco. Plant Cell Tissue Organ Cult. 113, 41-49. doi: 10.1007/s11240-012-0249-z

Streatfield, S. J. (2007). Approaches to achieve high-level heterologous protein production in plants. Plant Biotechnol. J. 5, 2-15. doi: 10.1111/j.1467-7652. 2006.00216.x

Tarassoff, C. P., Arlen, P. M., and Gulley, J. L. (2006). Therapeutic vaccines for prostate cancer. Oncologist 11, 451-462. doi: 10.1634/theoncologist.11-5-451

Twyman, R. M., Stoger, E., Schillberg, S., Christou, P., and Fischer, R. (2003). Molecular farming in plants: host systems and expression technology. Trends Biotechnol. 21, 570-578. doi: 10.1016/j.tibtech.2003.10.002

Vihko, P., Virkkunen, P., Henttu, P., Roiko, K., Solin, T., and Huhtala, M.-L. (1988). Molecular cloning and sequence analysis of cDNA encoding human prostatic acid phosphatase. FEBS Lett. 236, 275-281. doi: 10.1016/0014-5793(88)80037-1 
Zeng, F., Qian, J., Luo, W., Zhan, Y., Xin, Y., and Yang, C. (2010). Stability of transgenes in long-term micropropagation of plants of transgenic birch (Betula platyphylla). Biotechnol. Lett. 32, 151-156. doi: 10.1007/s10529-009-0120-4

Conflict of Interest Statement: The authors declare that the research was conducted in the absence of any commercial or financial relationships that could be construed as a potential conflict of interest.
Copyright (c) 2017 Kang, Kim, Myung and Ko. This is an open-access article distributed under the terms of the Creative Commons Attribution License (CC BY). The use, distribution or reproduction in other forums is permitted, provided the original author(s) or licensor are credited and that the original publication in this journal is cited, in accordance with accepted academic practice. No use, distribution or reproduction is permitted which does not comply with these terms. 